\title{
Three Decades of the Integrated Child Development Services Program in India: Progress and Problems
}

\author{
Niyi Awofeso ${ }^{1,2}$ and Anu Rammohan ${ }^{3}$ \\ ${ }^{1}$ School of Population Health, University of Western Australia, \\ ${ }^{2}$ School of Public Health and Community Medicine, University of New South Wales \\ ${ }^{3}$ Discipline of Economics, School of Business, University of Western Australia \\ Australia
}

\section{Introduction}

It is understood that life success, health and emotional wellbeing have their roots in early childhood. Investing resources to support children in their early years of life brings long-term benefits to them and to the whole community. Early childhood development outcomes are therefore important markers of the welfare of children, and can predict future health and human capital. Well conducted research studies show that Early Child Development programs benefit children, families, and communities, and are associated with; higher and timelier school enrolment, higher school completion rates, improved nutrition and health status, child morbidity and mortality, improved social and emotional behaviour, and increased earning potential and economic self-sufficiency as an adult (Reynolds et al., 2001; Young, 1996).

Over the past three decades, India has experienced high prevalence of malnutrition despite increasing agricultural production and enviable economic growth. Some analysts have attributed this to poverty, spending patterns which favour festivals and non-essential foodstuffs over staple food, and high rates of infectious and chronic diseases (Banerjee \& Duflo, 2006; Radhakrishna \& Ravi, 2004). India's governments have sought to address chronic malnutrition through an extensive network of food-based social safety net, price controls for staple foods, income support, food-for-work programmes and direct provision of nutritious food to children. By far the biggest nutrition supplementation programme in India is the Integrated Child Development Services (ICDS).

Early childhood care and education services were prioritised in India's 1986 National Policy on Education as a crucial input into primary education and a significant support for women wishing to work in the formal sector. An inter-ministerial survey in 1972 revealed that child care programmes in India were not having the desired impact owing to resource constraints, inadequate coverage, and a fragmented approach. Consequently, India's ICDS was established in 1975 with the following objectives; (1) lay the foundation for the physical, psychological and social development of children; (2) improve the nutritional and health status of children in the age group 0-6 years and reduce the incidence of mortality, sickness, malnutrition and school dropout; (3) enhance, through improved health care and education, the ability of mothers to look after the normal needs of their children, and; (4) achieve 
effective co-ordination of policy and implementation among various departments responsible for child development (Kaul, 1993). The ICDS is estimated to be the world's largest integrated early childhood program, with over 40,000 centres established nationwide. The program covers over 4.8 million expectant and nursing mothers and over 23 million children under the age of six. Of these children, more than half participate in early learning activities. The network consists of 3907 projects, covering nearly 70 per cent of the country's community development blocks and 260 urban slum pockets.

ICDS programs are delivered through a network of projects in slum, rural or tribal areas. Rural or urban projects cater for populations of about 100,000 people divided into 100 centres or Anganwadis (literally courtyards), while tribal projects cater for populations of about 35,000 people divided into 50 centres. Each centre has a trained paraprofessional or Anganwadi worker - generally a local woman proposed by the community and trained for three months in health and nutrition education, community support and participation, preschool education and record maintenance. Each project has four or five supervisors and one Child Development Officer who is responsible for the management and implementation of the entire programme in her/his jurisdiction (Lokshin et al, 2005). For children aged below 6 years, the core services offered for children are supplementary nutrition, immunisation, basic health care such as anti-helminth treatment, referral services to hospitals and health centres, non-formal pre-school education. For mothers, the core services offered are tetanus immunisation for expectant mothers, supplementary nutrition and health education (Muralialharari \& Kaul, 1993). The ICDS services are delivered almost exclusively at the Anganwadi, or childcare centre. Each centre is run by an Anganwadi worker and one helper, who undergo three months of institutional training and four months of communitybased training. The cost of the ICDS program averages $\$ 10-\$ 22$ per child a year (Dasgupta et al, 2005).

As at March 2008, the ICDS comprised 6120 operational projects and 1053006 Anganwadi centres, which reached about 58.1 million children (and 10.23 million pregnant or lactating women) , compared with 27.5 million children enrolled in 2000 (Kapil, 2002).

Despite increasing funding of the ICDS program over the past three decades, the ICDS has so far fallen short of its stated objectives. India's sub-optimal maternal and child health and education programs are exemplified by the following trends: India slipped from Millennium Development Goals (MDG) rank 128 in 2008 to 134 in 2009; India accounts for 50\% of the world's hungry; At least 46\% of Indian children are undernourished; in 2006, on average 254 women died giving birth to a child for every 100,000 live births relatively modest reduction from 327 in 1990. The states of Assam, Bihar, Chhattisgarh, Jharkhand, Madhya Pradesh, Orissa, Rajasthan, Uttar Pradesh and Uttaranchal had the highest numbers ranging from 480 to 312. Kerala at 95, Tamil Nadu at 111 and West Bengal at 141 fared less badly; Across India 74 children died before they reached the age of five for every 1,000 live births in 2005-06 as compared to 125 in 1990. At this rate India is likely to miss the target of reducing under-five mortality rate to 42 for 1,000 live births by 2015; About 400,000 infants die in the first 24 hours of their life and 90 per cent of deaths are due to preventable diseases like pneumonia and diarrhoea; India ranks 171 out of 175 countries in the world in public health spending; Despite $10.7 \%$ of the national budget devoted to education, only $61.9 \%$ of adult Indians aged over 15 years in 2008 (73.2\% males and 56.9\% females) were literate; India's measles vaccination coverage in India increased from $54 \%$ in 2000 to $70 \%$ in 2008 , but this coverage is much lower than the 2008 global coverage of $83 \%$. India achieved $23 \%$ measles mortality reduction between 2000 and 2008, but still accounts for two- thirds of the remaining global mortality 
from measles in 2008; the proportion of underweight (severe and moderate) children below three years of age declined only marginally during 1998-99 to 2005-06, from about 47 to $46 \%$ and at this rate of decline is expected to come down to about $40 \%$ only by 2015 (UN, 2010; UNESCO, 2010; WHO, 2009).

The lack-lustre trends in children's nutrition in India occurred despite increased funding for the ICDS program, from \$US35m in 1990 to \$US170m in 2000, and a 2005 decision by the Indian government to accord high priority to the expansion of the ICDS program. Although major reforms in public health, and particularly in maternal and child health, are urgently required in India, it is debatable whether the management of the ICDS program is appropriate for the formidable maternal and child health challenges it was established to address. It is noteworthy that India's youth literacy rate increased from $61.9 \%$ in 1991 to $79.3 \%$ in 2008 . India's 2009 MDG report (GI, 2010) projects a youth literacy rate of at least $98 \%$ by 2015 . Thus, this chapter will be focussed on health-related components of the ICDS program.

A 2006 World Bank study of the ICDS (Lokshin et al, 2005) determined that the programme had little overall effect on nutritional outcomes, and that the only significant effect of the programme was a positive effect on boys' stunting in the data from the 1992 survey, but not in 1998. For girls, the effect was not significant. At regional levels, the only significant finding was a negative impact in the poor Northern states, and in the Northeastern states. There, children living in an ICDS village had a higher probability of being underweight in the 1998 survey. This chapter examines health management aspects of the operations of the ICDS program, with a focus on under-nutrition of children aged $0-3$ years. Our central thesis is that sub-optimal health management is a major encumbrance to the realisation of the objectives of the ICDS program, especially in relation to improving children's nutrition levels.

Since malnutrition in India is mainly caused by inadequate nutrition, infectious diseases and poor sanitation, we also review public policies on food security. Public health services remain an important and cost-effective means of lowering the population's susceptibility to disease. According to Jalan and Ravallion (2003), the number of child deaths due to unsafe water is higher in India than any other country. Furthermore, World Bank estimates show that nearly a fifth of the rural Indian population does not have access to safe drinking water. It is therefore important that India's public and child health programs be complemented with community-based programmes that are specifically aimed at preventing under-nutrition and the spread of infectious diseases. India's public health and family health programs should include (at least on paper) infrastructure (water, sanitation, food storage, buildings), income generation, and provision of welfare and health safety nets. Community involvement and ownership are crucial, in contrast to the top-down delivery of health care in India (parts of which, like supplies, equipment, and trained personnel, remain necessary). Community-based, nutrition programmes have an important role in ensuring wide and timely coverage of key health services, such as immunization. Women's visits to health services, whether for curative or preventive child health care, are excellent opportunities for health workers to provide health and nutrition preventive services to women (e.g., education, counselling, and micronutrient supplements). This chapter utilises data on India's Family health surveys as well as government reports and scholarly articles to review health management facets of the ICDS, and proposes integrated strategies for revitalising India's child health services.

\section{Review of health management aspects of ICDS}

ICDS services are provided through a vast network of ICDS centres, better known as "Anganwadi". The term Anganwadi developed from the idea that a good early child care 
and development centre could be run with low cost local materials even when located in an 'Angan' or courtyard. The Anganwadi centre is operated by a modestly paid Anganwadi worker, assisted by an Anganwadi helper or Sahayika. The local Anganwadi is the cornerstone of the ICDS programme. The basic responsibility for implementing the programme rests with the State Government. The nodal department responsible for implementing ICDS at the state level is typically the Women and Child Development Department, or sometimes a related department (e.g. the Social Welfare Department). One Anganwadi worker is allotted to a population of 1000 . However, this differs by state, with relatively affluent states having a better staff to child ratios. In order to provide supplementary nutrition, cooked food is provided to the children in the age group of 2-6 years, expectant and lactating mothers and adolescent girls. The Supplementary Nutrition Programme aims to provide up to 300 calories and 8-10 grams of protein to the children and 500 calories and 20-25 grams of protein to the lactating mothers, pregnant ladies and adolescent girls. Severely malnourished children are given double diet as compared to a normal child. Immunization services are provided to all children below six years of age, who are immunized against tuberculosis, diphtheria, whooping cough, tetanus, polio and measles.

Of all childhood nutrition programmes in India, the ICDS is the only one with federal legislative backing. For example, in 2006, On 13 December 2006, India's Supreme Court stipulated that the Government of India shall sanction and operationalize a minimum of 14 lakh AWCs in a phased and even manner starting forthwith and ending December 2008. The ruling stated that, while maintaining the upper limit of one AWC per 1000 population, the minimum limit for opening of a new AWC is a population of 300 may be kept in view. All the State Governments and Union Territories were directed to fully implement the ICDS scheme by, inter-alia, allocating and spending at least Rs.2 per child per day for supplementary nutrition out of which the Central Government shall contribute Rs.1 per child per day; allocating and spending at least Rs.2.70 for every severely malnourished child per day for supplementary nutrition out of which the Central Government shall contribute Rs.1.35 per child per day; allocating and spending at least Rs.2.30 for every pregnant women, nursing mother/adolescent girl per day for supplementary nutrition out of which the Central Government shall contribute Rs.1.15. (Right to Food campaign, 2007) .

Tarozzi and Mahajan (2007) documented an increase in gender inequality in nutritional status in India over the 1990s, with the nutritional status of boys improving substantially more than that of girls. Gragnolati et. al (2005) attribute much of the child malnutrition in India to the high levels of exposure to infection and inappropriate infant and young child feeding and caring practices in the first two to three years of a child's life. A persistent decline in per capita calorie consumption in India over the last twenty years has been documented (Deaton and Dreze, 2008; Ray, 2007) The declining trend occurred across all income levels, and at a point when the nutritional measures for children are worsening.

Program placement: Coverage of ICDS is modest relative to need. In 2009, it benefitted 34 million children aged 0-6 years and 7 million pregnant and lactating mothers. Programme coverage is especially high in the southern region, the north-eastern region, and the nonpoor states of the northern region. Of the villages sampled by the NFHS, a third had an ICDS programme in place in 1992, and the figure had risen to more than half in 1998. The need for the ICDS program appears to be particularly high in the poor northern states of Bihar, Madhya Pradesh, Orissa, Rajasthan and Uttar Pradesh, where the proportion of stunted and underweight children exceeded 50\% in the 1992 and 1998 surveys. The 
proportion of villages covered by ICDS activities in these region increased, on average from 28\% to $43 \%$ between 1992 and 1998, compared with increases from 58\% to 82\% between 1992 and 1998 in the rich northern states of Gujarat, Haryana, Maharashtra and Punjab. The programme coverage is regressive relative to need, expenditure per child, and economic performance of the states. The states with the highest prevalence of stunted and underweight children, such as Bihar and Uttar Pradesh tend to have the lowest programme coverage. In 2001/2002, government expenditure per undernourished child in the 'rich' north states averaged 235 rupees, compared with 97 rupees in the 'poor' north states. Bihar (the poorest state) receives only Rs 25 per malnourished child, while Punjab (the richest state) receives Rs 334 . Ironically, due to poor governance, Bihar spent only $76 \%$ of its ICDS allocation in 2003, compared with $98 \%$ of allocated ICDS funds spent by Punjab in the same year (Lokshin et al, 2005). The average resident in Bihar is at least four times poorer than the average person in Punjab. Bihar's government health expenditure per person in 2005 was 84 rupees, compared with 251 rupees in Punjab. Bihar's 2007 per capita income was 13663 rupees, compared with Punjab's 27,873 rupees (Berham \& Ahuja, 2008). Based on wealth rankings, richer villages have a higher probability of being covered by the programme than poorer ones. For example, only half of the villages from the lowest two income deciles had the ICDS programme in place in 1998, while about 80 per cent of the richest villages in India were covered (Radhakrishna \& Ravi. 2004).

Equity issues: Program placement closely reflect equity issues, but extend to include analysis of persistent inequalities in maternal and child health outcomes based on income level., caste, gender or rural residence. A recent analysis of trends in infant undernutrition in India between 1992 and 2005 using the nationally representative family health survey (Subramanyam et al, 2010) revealed that the overall prevalence (\%) of underweight was 49.14, 43.82 and 40.26 in 1992, 1998 and 2005 respectively. The corresponding prevalence (\%) of stunting was 52.43,50.65, and 44.73. Social disparities in undernutrition over these 14 years either widened or stayed the same. The absolute rates of undernutrition decreased for everyone regardless of their social status. The disparities by household wealth were greater than the disparities by maternal education. There were no disparities in undernutrition by caste, gender or rural residence. Maternal education is improving, with the female literacy parity index of youths increasing from 0.64 in 1991 to 0.81 in 2001, and projected to reach parity by 2015. The bulk of the increase was in the poor states. For example, in Bihar, the female literacy rate in 2001 was $34 \%$, compared with male literacy rate of $60 \%$. By providing bicycles for year 9 and 10 students, and providing school uniforms free of charge to women, Bihar increased its year 9 enrolment of girls in year 9 by 170,000 in 2007, compared with 2006 prior to the commencement of the scheme However, addressing income inequity, the most influential determinant of infant undernutrition in India, remains a major challenge. The proportion of people below the national poverty line estimated for 1990 was $37 \%$. By the year 2004-05, the poverty headcount ratio declined to $28 \%$. The poorer and relatively populous states such as Bihar, Jharkhand, Chhattisgarh, Madhya Pradesh had about 193.5 million of people below poverty line in 2004-05 (64\% of total people below poverty line) and are expected to have nearly 198 million people below poverty line in 2015 (71\% of total people below poverty line (GI, 2010). Despite claims of rapid economic growth by Bihar and several other poor states, outmigration, poverty and inefficient health administration have not translated economic gains into significant improvements in maternal and child health. Public health facilities are typically allocated on the basis of population (Koenig et al., 2000). However, the quality of services is likely to depend on the level of economic development in the region; owing to the difficulties of relocating skilled medical personnel in remote areas. 
In India, the Panchayati Raj Act has placed emphasis on building local government, and devolving health activities to them.

However, a rapid rise in private providers of healthcare, with a subsequent increase in its utilisation can in turn influence the quality of care in public facilities (Peters et al., 2002). According to Bhargava et al. (2005) the healthcare infrastructure in India has evolved gradually over time and comprises of public facilities, private providers and NGO's. Initially, healthcare was available mainly in urban areas via government facilities and from private practitioners offering services to those who can afford them. Urban settings are considered to be more attractive to medical personnel, thereby restricting the pool of medical practitioners prepared to work in rural areas. This increase in supply of urban doctors has improved the quality of medical services in urban areas.

Government health expenditure in India is relatively low compared to other countries in the region and has actually declined over the last two decades. According to Bhalotra (2007), while government health expenditure constituted 1.3\% of the GDP in 1990, this had declined to $0.9 \%$ in 1999 . Relative to other countries in the region, India devotes a smaller share of its income to health spending than, for example, Bangladesh $(1.4 \%)$ or Sri Lanka $(1.8 \%)$ (Deolalikar 2005), and it spends a disproportionate part of its health budget on (curative) hospital services which are less pro-poor than (preventive) public health expenditures (Peters et al. 2002).

Jalan and Ravallion (2003) found a significantly lower prevalence and duration of diarrhoea among children living in households with piped water. Health gains from piped-water tend to be lower for children with less well-educated women in the household. It is possible that education is acting as a proxy for knowledge about how to assure that water is safe to drink and how best to treat illness. The income effect on the child-health benefits from piped water is also found at given levels of education, though it is not as pronounced. This is consistent with a previous study by Rajna et al (1998) which used data from the 1992-1993 National Family and Health Survey in India to show that improvements in health services, maternal education and provision of safe drinking water have had a desirable impact on child survival in Uttar Pradesh.

Health workforce: The World Health Report 2008 and the 62nd World Health Assembly resolution strongly reaffirmed the principles of primary health care. These principles include equity, solidarity, social justice, universal access to services, multi-sectoral action, decentralization and community participation as the basis for strengthening health systems and optimising the quality of health services (WHO, 2008). Member states were urged to train and retain adequate numbers and mix of health workers able to work in a multidisciplinary context $(\mathrm{GO}, 2006)$. The ICDS was conceptualised as a primary health care initiative, but not enough has been done so far to develop and retain adequate health workforce in terms of quantity, quality and distribution. There are around 1.5 million women workers engaged in the Anganwadi projects across India. Although each ICDS is staffed by several Anganwadi and community health officers (most of whom are Anganwadi with several years' experience), and headed by a maternal and Child Development Officer, the front-line staff is the Anganwadi, local women proposed by an ICDS village and trained in health and nutrition for at least three months. The Anganwadi workers are not normally gazetted as government workers, but are rather paid as casual staff. Anganwadi workers are expected to have completed high school. Those with less than high school education are employed as Anganwadi helpers. In announcing the 2008-2009 Budget, Indian Finance Minister Chidambaram stated that minimum salaries would be 
increased for Anganwadi workers to Rs 1500 (\$US36) per month and helpers to Rs 750 (\$US18) per month. In the public sector, the national minimum wage since 2009 is Rs 100 per day. On 4 May 2010, hundreds of Anganwadi workers from various parts of India staged a protest march in New Delhi demanding higher wages, job security and status of government servants with privileges of pension and allied retirement benefits. The wide inequity in remuneration between Anganwadi workers and the least paid Indian government employees is a major demotivating factor for the core human resource sector of the ICDS programme. There are also wide regional differences in salaries paid to Anganwadi, and this is a major source of perceived unfairness and demotivation for relatively lower paid staff. For example, in Puducherry, Anganwadi workers are paid Rs 12,000 per month workers and Anganwadi helpers paid Rs 6,000 monthly, compared with Rs 2000 monthly for Anganwadi workers and Rs 1200 monthly for helpers in Kamataka. Such perceived unfairness, coupled with other workforce-related encumbrances affecting Anganwadis, contribute to sub-optimal performance of this cadre of workers (Figure 1).

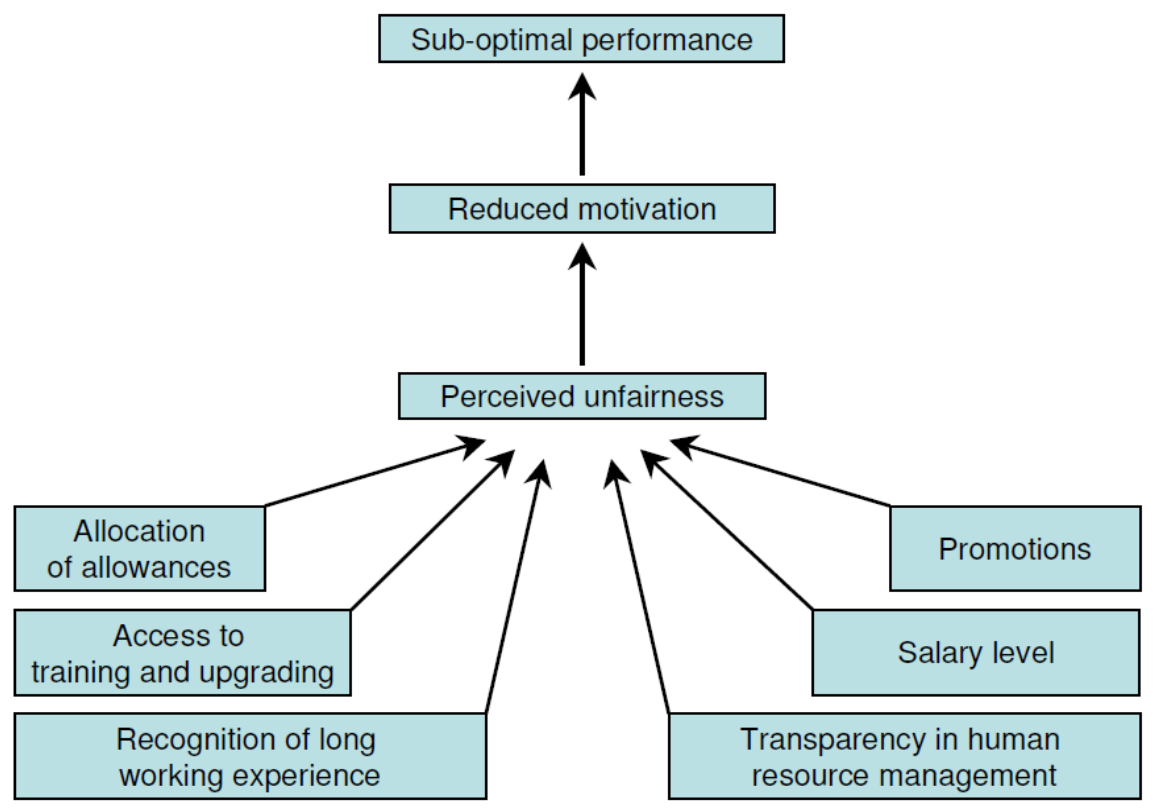

Fig. 1. Factors influencing health workers performance (Source;

http://www.biomedcentral.com/content/pdf/1472-6963-11-34.pdf)

There are wide variations in the competence of Anganwadi workers, with some workers, particularly in the wealthier states having tertiary educational qualifications. It is in the most vulnerable states such as Bihar that qualified Anganwadi workers are in short supply. The distribution of Anganwadi workers is not fluid - being almost exclusively women, Anganwadi staff generally work in their areas of residence. Cultural encumbrances as well as lack of formal recognition of this cadre of workers are additional disincentives for mobility to underserved areas. Thus, areas with low female literacy are unlikely to have qualified Anganwadi workers. Such health workforce shortages explain why the ICDS 
program may paradoxically result in negative maternal and child health outcomes in poorer and remote regions of India where female education is low. Consequently, many centres, particularly in the poorer states such as Orissa are staffed by Anganwadi helpers, and these staff lack the necessary qualifications for the level of in-service training they are regularly invited to attend (GO, 2006; Udani et al, 1990). It is unrealistic to expect a high school graduate with three months training to adequately perform some of the tasks entrusted to Anganwadi workers, such as pre-school and health education, maintenance of records of births and deaths, administration of pulse-polio drops, and provision of supplementary nutrition to pregnant and lactating mothers and children up to the age of six. Access to Anganwadi training is inequitable. As at January 2008, Andhra Pradesh, whose maternal and child health indicators are higher than the national average, had 66 accredited Anganwadi training centres, while Bihar had none and Sikkim had only one, despite these two states having high levels of infant malnutrition and inferior maternal health outcomes compared with national average. In relation to food provision, for example, many states provide pre-packaged food which the Anganwadi workers describe as unpalatable to enrolled children. As a result, some Anganwadi workers have had buy food for severely malnourished children from their paltry salaries - a source of significant job dissatisfaction. Since 2009, Anganwadi workers and helpers have been advocating that the food preparation and supply must be localised and the responsibility for food procurement and preparation must be given to women's organisation instead of contractors, as is the case in Kerala and Tamil Nadu (Radhakrishna \& Ravi, 2004).

Strategic approach to addressing undernutrition: A 2008 study of reasons for poor performance of health workers entailed interviews of Anganwadi and mothers in rural Wardha, Sewagram. Mothers of children enrolled in ICDS programs in this region lamented the poor quality of supplementary food. They reported that Khichari, a preparation of rice and dal (pulses), a common supplementary food, contained very little oil and dal component. So children refused to eat it every day. Although, there was variety in the supplementary food available, such as use of sprouted grains and green peas, they were less frequently prepared. Anganwadi, on their part listed the 12 most common reasons for the limited success of ICDS: 1) poor cooperation from villagers; 2) poor understanding of parents; 3) mothers do not follow medical advice; 4) mothers are busy with farm work; 5) Irregular and poor health check-up service; 6) mothers do not follow dietary advices; 7) poor personal hygiene of families; 8) poverty; 9) poor environmental sanitation; 10) poor child care practices; 11) poor support from authorities, and 12) various social problems. This survey also revealed that most of the workload of Anganwadi workers is taken up in paperwork and attendance at workshops, which significantly reduce the time devoted to their core ICDS duties (Dongre et al, 2008). Although the ICDS is the most well-known of India's national dedicated maternal and child health nutrition and education program, there are at least two other national and 10 regional nutrition and education programs in India, including National Mid-day Meal Scheme, the National Rural Health Mission, Comprehensive Rural Health Project, Integrated Nutrition and Health Program and the Public Distribution System. These programs appear to compete rather than collaborate with one another in the achievement of optimal maternal and child health outcomes (Tarozzi, 2002; Mann et al, 2010). India's public health system, on which all maternal and child health programs rely is poorly funded and poorly functioning. From an expenditure perspective, government spending on health per capita increased from Rs 202 to Rs 257 between 2000 and 2005. Adjusting for inflation, this increase is modest - Rs 215 in 2005. However, as percentage of GDP, India's government 
health spending actually fell from $1.12 \%$ in 1999 to $0.97 \%$ in 2005 (Berman \& Ahuja, 2008). In terms of fulfilment of public health functions, a 2004 World bank evaluation found that although India's public health system has the capacity to carry out its public health functions, the system has major weaknesses in relation to persistently overlooking fundamental public health functions such as public health regulations and their enforcement; "deep management flaws", which hinder effective use of resources, including inadequate focus on evaluation; on assessing quality of services; on dissemination and use of information; and on openness to learning and innovation; "the central government functions too much in isolation and needs to work much more closely with other key actors, especially with sub-national governments, as well as with the private sector and with communities." (Das Gupta et al, 2004). Given inadequate funding and flawed management of the public health system, the platform on which the ICDS relies is weak. India's weak public health system partly explains the insignificant impact of the program on maternal and child health outcomes. Child malnutrition is mostly the result of high levels of exposure to infection and inappropriate infant and young child feeding and caring practices, and has its origins almost entirely during the first two to three years of life. The ICDS program, while successful in many ways, has not made a significant dent in child malnutrition. This is mostly due to the priority that the program has placed on food supplementation, targeting mostly children after the age of three when malnutrition has already set in. Compared to 1990, 10,000 fewer children in India died daily before reaching their fifth birthday in 2009. However, India still accounted for $21 \%$ of global under-five mortality in 2009. The infant mortality rate declined $40 \%$, from $83.8 \%$ in 1990 to $50.3 \%$ in 2009 , while the under-five mortality rate declined 45\%, from 118 in 1990 to 65.6 in 2009 (UN, 2010). The slower decline in infant mortality rate reflects, in part the inappropriate strategy of the ICDS in focussing food supplementation on children aged 37 to 59 months, with less attention paid to encouraging breast feeding and providing adequate supplementary feeding to infants.

Maternal feeding and caring behaviour: Maternal feeding and caring behaviour is mediated by sociocultural environments of households, including the impact of religion and parental education and wealth status. A 2005 study of 408 children aged $1-3$ years enrolled in an ICDS program in north India found that 199 (48.7\%) children were underweight and $79.2 \%$ of children had dietary calories intake below $80 \%$ of recommended dietary intake. Advice regarding breast feeding and/or complementary feeding was given by Anganwadi workers to only $179(43.8 \%)$ women (Prinja et al, 2008). The ICDS program has not achieved any major success in improving behavioural outcomes such as timely initiation of breast feeding $(16.7 \%)$ and complementary feeding (39.9\%). Prevalence of exclusive breast feeding has remained low at $28.2 \%$. Although other factors including socio-economic conditions, sociocultural beliefs and literacy status determine child feeding practices, the low proportion of women who reported to have been advised by the Anganwadi worker regarding breast feeding and complementary feeding reflects the deficiency of the program (Prinja et al, 2008). The percentage of pregnant women who had at least three antenatal care visits in 2008 was $51 \%$, and only $47 \%$ of deliveries were attended by skilled birth attendants. Antenatal care attendance is a strong predictor of maternal caring behaviour (Halim et al, 2010). An important gap in maternal feeding practices is exclusive breastfeeding for the first four months of infancy. A 2003 study in urban and rural areas of Latur and Osmanabad districts of Maharashtra State revealed that exclusive breastfeeding for the first four months was undertaken by $40 \%$ of mothers. Such inadequacies predispose infants to malnutrition and infection (Kameswararao, 2004). 
Micronutrient deficiencies - Iron and vitamin A: According to the World Health Organization's 2009 Global health risks' report (WHO, 2009), iron deficiency anaemia accounted for 400,000 deaths and 1.5\% of the global Disability Adjusted Life Years in 2004. This cost is disproportional borne by developing nations as $60 \%$ of the morbidity and $95 \%$ of the mortality related to iron deficiency are derived from the poorest nations of the world. Despite increased national and international awareness and recent governmental intervention programs, the prevalence of anaemia among Indian women has remained higher than $45 \%$ since 1990, and anaemia trends remain strongly correlated with iron deficiency. A 2007 Indian government "12 by 12 initiative", aimed at ensuring that all Indian adolescents have $12 \mathrm{~g} / \mathrm{dL}$ haemoglobin by 2012 , listed the main causes of anaemia in India as low dietary intake, poor availability of iron, chronic blood loss due to hookworm infestation, and malaria (MOHFW, 2006). Although serum iron monitoring is not a major duty of Anganwadi workers, they can contribute to screening for iron deficiency indirectly through growth monitoring, which is a core duty. Unfortunately, it has been been reduced to routine of weight recording, with less than $3 \%$ of mothers in one ICDS-related study having knowledge of nutritional status of their child in terms of the growth chart (Prinja et al, 2008). Despite mothers stating that lack of nutritious food is the prime reason for their infants' undernutrition, the food provided by many Anganwadi centres is not palatable and most enrolled pupils do not eat adequately. In India as at 2008, 60.8 million children are chronically undernourished, representing $48 \%$ of all undernourished children aged less than 5 years globally. Almost all these undernourished children suffer from iron deficiency anaemia (Pada, 2010). In India, anaemia is the second most common cause of maternal death, accounting for $20 \%$ of total maternal deaths. Multiple studies show that at least $45 \%$ of all Indian women are anaemic, based on WHO criteria. Most anaemic mothers are malnourished, and are more likely to deliver malnourished babies (WHO, 2008). The main underlying cause of vitamin A deficiency as a public health problem is a diet that is chronically insufficient in vitamin A that can lead to lower body stores and fail to meet physiologic needs (e.g. support tissue growth, normal metabolism, resistance to infection). Deficiency of sufficient duration or severity can lead to disorders such as xerophthalmia (xeros = dryness; - ophthalmia = pertaining to the eye), the leading cause of preventable childhood blindness, anaemia, and weakened host resistance to infection, which can increase the severity of infectious diseases such as measles and risk of death. Good plant sources of vitamin A include spinach, carrots and oranges. Based on biochemical measurement, vitamin A deficiency is a public health problem in India, with over $5 \%$ of children affected [Figure 2] (WHO, 2009b). Although biochemical retinol measurements are not part of Anganwadi workers duties, they could be easily trained in detecting vitamin A deficiency using characteristic eye signs of vitamin A deficiency, such as bitot spots - superficial, irregularly-shaped, foamy grey or white patches that appear on the conjunctiva, the membrane that covers most of the eyeball. More importantly, the foodstuffs supplied at ICDS centres need to be prepared such that they are nutritious, balanced and palatable. Given the high incidence of nutritional blindness in India, provision vitamin A supplements may be included in the duties of Anganwadi staff. In a longitudinal study designed to assess the impact of a massive-dose vitamin A programme on the incidence of keratomalacia, 50000 preschool children in 450 slum areas in India's Hyderabad city were given 200000 IU of vitamin A once every 6 months. During the study period, the incidence of keratomalacia in areas covered by the programme decreased by about $80 \%$, while in control areas the reduction 
was of the order of $20 \%$. To test whether large doses of vitamin A supplements prevented keratomalacia, a case-control analysis was done, with patients with severe protein-energy malnutrition being used as controls. The high odds ratio clearly indicated that keratomalacia was more likely to occur in children not receiving supplements (Vijayaraghavan et al, 1984)

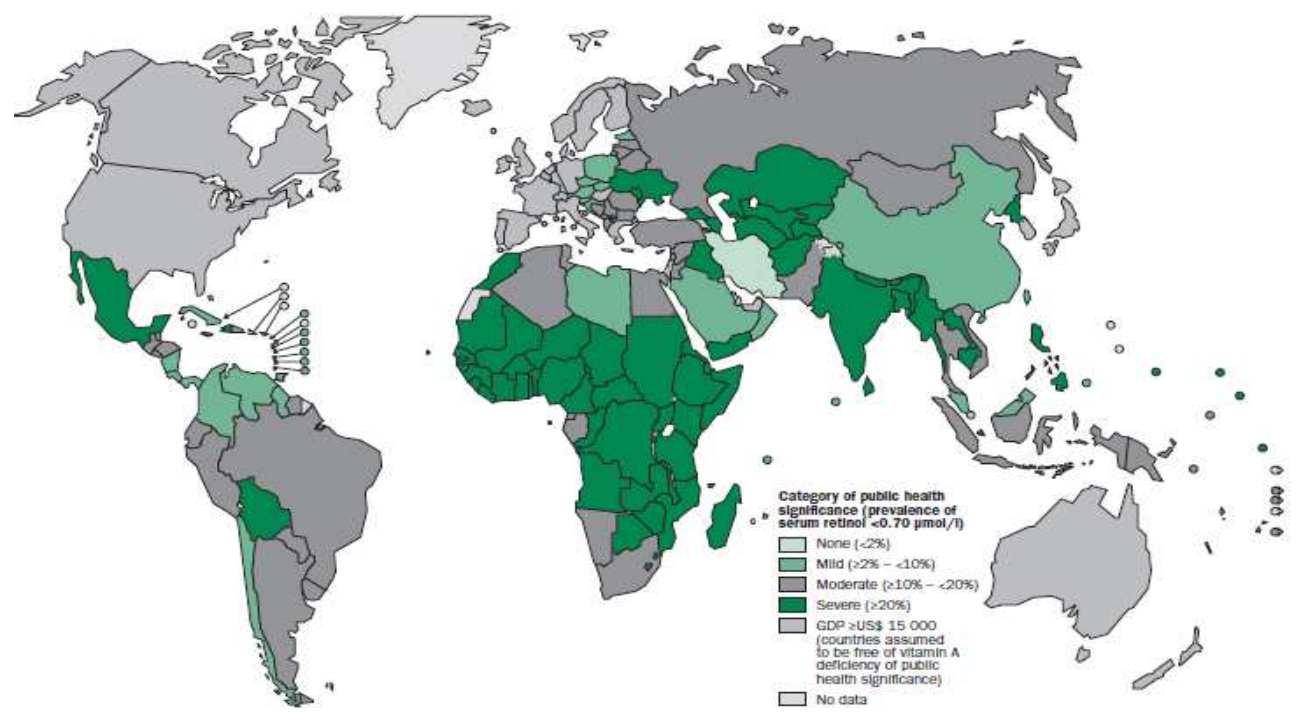

Fig. 2. Global Vitamin A deficiency prevalence (Source: WHO, 2009b).

ICDS infrastructure: The infrastructure for ICDS clinics is sub-optimal to facilitate achievement of its objectives. Although total budgetary allocation for the ICDS scheme increased from Rs. 529300.00 Lakh in 2007/2008 to Rs. 670500.00 Lakh in 2009/2010, this budget translates to less than 2 rupees per enrolled child and mother per day, and there is very little to show for such funding increases in the area of infrastructure. For example, a report of unannounced visits by the Karnataka State Commission for Protection of Child Rights to ICDS centres in 13 districts between July 2009 and July 2010 revealed cramped Anganwadi centres with no toilets for children, stale bread passed on as 'hot meals', drab walls without any charts as characteristic findings. Commission chairperson Nina Naik stated that there is an urgent need for "revisiting and redesigning the current ICDS programme in the interest of children". Low attendance was also found to be rampant, with just $20-25 \%$ of the enrolled children in the 3-6 year bracket going to ICDS centres. "Community seemed to have no confidence in the service and retain children at home or admit the 5-6 year olds into private pre-school services," observed the report. Similarly, a 2009 study of 65 ICDS centres in 10 districts of Madhya Pradesh found that, of the 65 centres studied only 24 (37\%) have suitable buildings. Only $72 \%$ of the studied centres had their own Salter children weighing machine, only $66 \%$ of the centres had adult weighing machines, and only $58 \%$ had growth registers (Samvad, 2009). A major contributor to poor ICDS infrastructure is corruption. For example, a recent Times of India report stated that, in the state of Assam, although the government allots Rs 175000 for each ICDS building, the state spends only Rs 30,000 in each of the buildings in reality (Times of India, 2011). 
Inadequate systems capacity building input into ICDS

Capacity building is any action that improves the effectiveness of individuals, organizations, networks, or systems-including organizational and financial stability, program service delivery, program quality, and growth. Capacity building is a long-term process that improves the ability of an individual, group, organization, or ecosystem to create positive change and perform better to improve public health results (MSH, 2010). A number of activities which have taken place under the banner of organisational capacity building in relation to the ICDS program have focussed on erecting buildings and providing training programs to Anganwadi workers.

A systems capacity building approach to improving the ICDS looks beyond training, and even the ICDS itself, into structural factors which may impact on child health and development. The starting point for improving child health and development is the Indian nubile female. Poorly nourished women are more likely to give birth to underweight infants, a major risk factor for both child as well as maternal morbidity and mortality (Kelly et al, 1996).A recent maternal nutrition study in Pune found that 33\% of Indian women have a BMI less than 17, implying significant underweight, compared with $14 \%$ of men (Chorghade et al, 2006). Improving maternal nutrition in India would entail addressing cultural, socio-economic and, knowledgebased and attitudinal impediments, a task beyond the scope of ICDS, but within the scope of India's public health system. Effective systems capacity building comprises optimal interaction of nine components [Box 1 and Figure 3] (Potter \& Brough, 2004):

- Performance capacity: Are the tools, money, equipment, consumables, etc. available to do the job? A doctor, however well trained, without diagnostic instruments, drugs or therapeutic consumables is of very limited use.

- Personal capacity: Are the staff sufficiently knowledgeable, skilled and confident to perform properly? Do they need training, experience, or motivation? Are they deficient in technical skills, managerial skills, interpersonal skills, gender-sensitivity skills, or specific role-related skills?

- Workload capacity: Are there enough staff with broad enough skills to cope with the workload? Are job descriptions practicable? Is skill mix appropriate?

- Supervisory capacity: Are there reporting and monitoring systems in place? Are there clear lines of accountability? Can supervisors physically monitor the staff under them? Are there effective incentives and sanctions available?

- Facility capacity: Are training centres big enough, with the right staff in sufficient numbers? Are clinics and hospitals of a size to cope with the patient workload? Are staff residences sufficiently large? Are there enough offices, workshops and warehouses to support the workload?

- Support service capacity: Are there laboratories, training institutions, bio-medical engineering services, supply organizations, building services, administrative staff, laundries, research facilities, quality control services? They may be provided by the private sector, but they are required.

- Systems capacity: Do the flows of information, money and managerial decisions function in a timely and effective manner? Can purchases be made without lengthy delays for authorization? Are proper filing and information systems in use? Are staff transferred without reference to local managers' wishes? Can private sector services be contracted as required? Is there good communication with the community? Are there sufficient links with NGOs?

- Structural capacity: Are there decision-making forums where inter-sectoral discussion may occur and corporate decisions made, records kept and individuals called to account for non-performance?

- Role capacity: This applies to individuals, to teams and to structure such as committees. Have they been given the authority and responsibility to make the decisions essential to effective performance, whether regarding schedules, money, staff appointments, etc?

Box 1. Nine component elements of systems capacity building applicable to improving the effectiveness of ICDS programme 


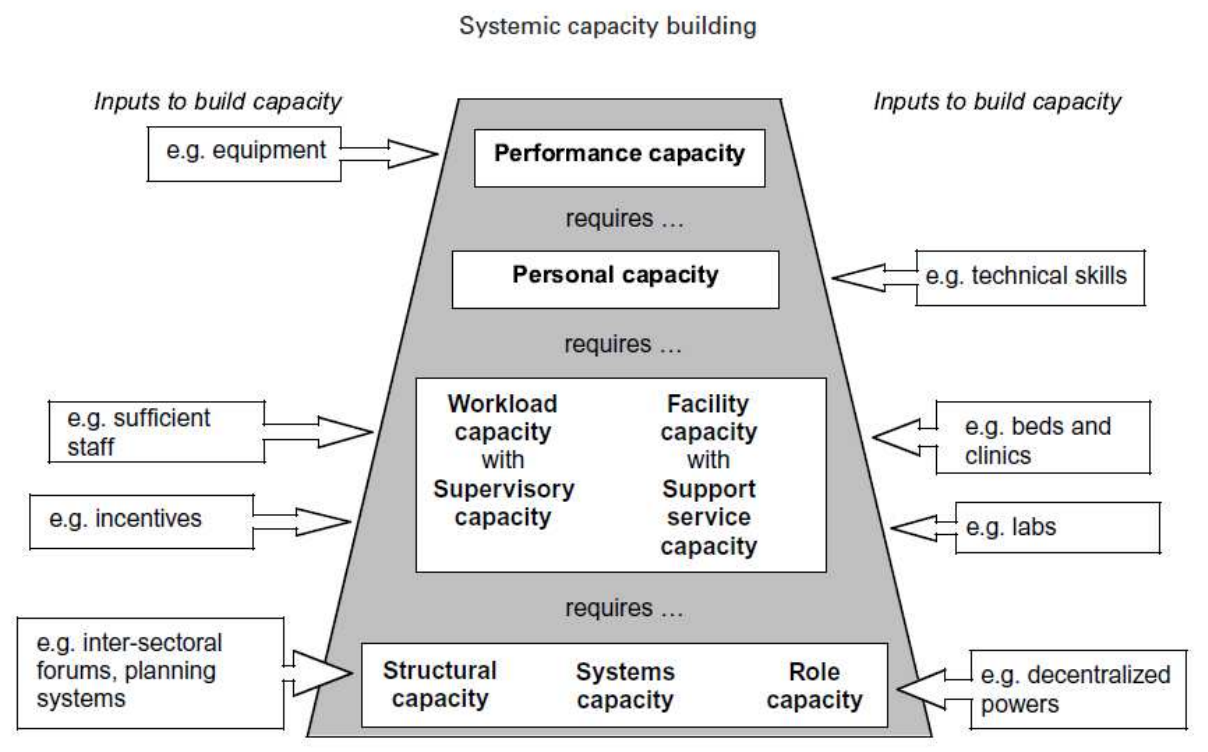

Fig. 3. Pyramid of effective capacity building

\section{Conclusion}

The ICDS has not met its objectives, three decades on, due in part to poor health management. A systems capacity building approach is proposed to improve the health and development of mothers and children in India. This approach entails a revitalised India's public health, rather than the ICDS, as a major facilitator of maternal and child health improvements. Issues that need to be addressed include; (1) Revitalising India's public health system, and providing adequate funding to make it more responsive to the needs of the whole population, instead of the over-reliance of vertical programmes such as ICDS; (2) Introducing sustainable poverty reduction programmes, particularly in areas with high maternal and child malnutrition. Improvement in maternal education is also very important in reducing maternal and child health. Remarkably, such improvements are already underway; (3) Expanding the depth and breadth of the training curriculum of Anganwadi workers and professionalising the cadre within India's public service. These workers require adequate remuneration commensurate with their job description, over and above the minimum wage in India's public sector; (4) Devolving the supply of ICDS food from pilfering contractors to local women groups. Employment of dieticians to facilitate adequate quantity (at least 500 calories per meal) and quality (i.e. rich in all food classes) of the meals served at Anganwadi centres. Home visits should be introduced, particularly for malnourished children, to work with the mothers of such children in the provision of nutritious meals at their respective homes; (5) Streamlining the wide array of existing maternal and child health programs, most of which have not demonstrated evidence of effectiveness, to assure quality implementation; (6) Targeting children from 1-3 years, as most of the malnutrition in children develop from this period, and most long term consequences of malnutrition may be minimised if this cohort of children are properly 
monitored nutritionally; Training and employment of health administrators to adequately manage the ICDS program; Focusing more on program outcomes, linked to child nutrition measures, rather than ICDS processes such as numbers of centres established; (7) Fortifying the food handed out by the PDS and those prepared at ICDS centres with micronutrients and vitamins, as this would be an economical and effective way to lower rates of anaemia and vitamins, and increase maternal and child nutrition; (8) Standardised building and equipment plans for ICDS centres should be established nationally, and only ICDS centres that meet minimum standards for building and equipment within a specified budget range should be allowed to operate. Such an approach will enhance the functioning of ICDS centres, and reduce fraudulent practices related to the construction of these sites.

\section{References}

Allen, Lindsay H. and Stuart R. Gillespie. (2001). 'What Works? A review of the efficacy and effectiveness of nutrition interventions', Manila: UN Administrative Committee on Coordination Subcommittee on Nutrition, in collaboration with the Asian Development Bank.

Berman, P, Ahuja R (2008). Government health spending in India. Economic and Political Weekly, June 28, pp 209-216.

Banerjee, AV \& Duflo, E. (2006). The economic lives of the poor. Journal of Economic Perspectives 21 (1), pp 141-168.

Bhalotra, Sonia (2007), 'Spending to Save? State Health Expenditure and Infant Mortality in India', IZA Discussion Paper No. 2914.

Bhargava, A., Chowdhury, S, and Singh, K.K.(2005), Healthcare infrastructure, contraceptive use and infant mortality in Uttar Pradesh, India, Economics and Human Biology, 3, 388-403.

Das Gupta, M, Michael Lokshin, M \& Ivaschenko, O (2005), Improving Child Nutrition Outcomes in India Can the Integrated Child Development Services Program Be More Effective?, World Bank Policy Research Working Paper 3647, June 2005.

Das Gupta M, Rani M. India's Public Health System: How Well Does It Function at the National Level? World Bank Policy Research Working Paper 3447, November 2004.

Deaton, A. and J. Dreze (2009). Food and Nutrition in India: Facts and Interpretations. Economic and Political Weekly, XLIV(7), 42 - 65.

Deolalikar, A. (2005), Attaining the Millennium Development Goals in India: How Likely and What Will It Take To Reduce Infant Mortality, Child Malnutrition, Gender Disparities and Hunger-Poverty and to Increase School Enrollment and Completion? Oxford University Press, New Delhi, 2005.

Dongre, AR, Deshmukh, PR \& Garg, BS (2008). Eliminating childhood malnutrition: discussions with mothers and Anganwadi workers. Journal of Health Studies, 1 (2-3), pp 48-52.

Government of India [GI] (2010). Millennium Development Goals: India Country report 2009. New Delhi: Ministry of Statistics and Programme Implementation, India.

Government of Orissa [GO] (2006). Training of trainers' manual for Anganwadi workers Kishori Shakti Yojana and Balika Mandal as strategies for empowering adolescent girls. Orissa, 2006. URL:

http://www.wcdorissa.gov.in/download/KSYTrainingoftrainerManualforAWWs.pdf Accessed 30-January 2011. 
Gragnolati, Michele, Shekar, M , Das Gupta, M, Bredenkamp, C and Lee, Yi-Kyoung (2005), 'India's undernourished children: A Call for reform and Action', Health, Nutrition and Population (HNP) Discussion Paper, The World Bank.

Greiner, Theodore, and David F. Pyle.2000. "Nutrition Assessment - India", paper presented at the World Bank-UNICEF Joint Nutrition Assessment Workshop, Oct 11-12, 2000.

Halim, N, Bohara, AK, Xiaomin, R. Healthy mothers, healthy children: does maternal demand for antenatal care matter for child health in Nepal? Health Policy and Planning, 2010, doi: 10.1093/heapol/czq040.

Jalan, Jyotsna and Martin Ravallion (2003) ‘Does Piped Water Reduce Diarrhea for Children in Rural India?' Journal of Econometrics Vol. 12(1): 153-73.

Kameswararao, AA (2004). Breast Feeding Behaviour of Indian Women. Indian Journal of Community Medicine, 19 (2), pp62-64

Kapil, U (2002). Integrated Child Development Services (ICDS) scheme: a program for holistic development of children in India. Indian Journal of Paediatrics; 69 (7), pp 597-601.

Kaul V. (1993). Integrated child development services in India. Childhood, 1 (4), pp 243-245.

Kelly A, Kevany J, de Onis M, Shah PM. (1996). WHO collaborative study of maternal anthropometry and pregnancy outcomes. International Journal of Gynecology \& Obstetrics, 53 (3), pp 219-223.

Koenig, M., Foo, G., Joshi, K., (2000), 'Quality of care within the Indian family welfare programme: a review of recent evidence', Studies in Family Planning, 31, 1-18.

Lokshin, M, Das Gupta, M, Gragnolati, M \& Ivaschenko O (2005). Improving Child Nutrition? The Integrated Child Development Services in India. Development and Change 36 (4), pp 613-640.

Management Sciences for Health (2010). Challenges Encountered in Capacity Building: Review of Literature and Selected Tools. Position Paper No. 10, 2010, p 2.

Mann, V, Eble, A, Frost, C, Premkumar, R, Booneb, P (2010). Retrospective comparative evaluation of the lasting impact of a community-based primary health care programme on under-5 mortality in villages around Jamkhed, India. Bulletin of WHO, 88 (10), pp 727-736.

Ministry of Health and Family Welfare [MOHFW], Government of India. Micronutrient National Investment Plan (IMNIP) for 2007-2011. Delhi; MOHFW, URL: http://www.micronutrient.org/CMFiles/MI\%20Around\%20the\%20World/Asia/I ndia-MN-Investment-Plan.pdf Accessed 23 January 2011.

Muralialharari R, Kaul V (1993). Responding to children's needs: Integrated Child Development Services in India. In: Elderling L, Leseman P. Early intervention and culture: preparation for literacy; the interface between theory and practice. UNESCO, ISBN 92-3-102937-1, Paris.

Pada, G (2010). Child malnutrition in India - putting the smallest first. The Economist, 23 September, URL: http://www.economist.com/node/17090948 accessed 27 January 2011

Peters, D., Yazbeck, A., Sharma, R., Ramana, G., Pritchett, L.,Wagstaff, A.(2002) Better Health Systems for India's Poor. World Bank, Washington, DC.

Prinja, S, Verma, R, Lal, S. (2008). Role of ICDS program in delivery of nutritional services and functional integration between Anganwadi and health worker in north India. The Internet Journal of Nutrition and Wellness. 2008 Volume 5 Number 2. 
Radhakrishna , R \& Ravi, C. (2004). Malnutrition in India - trends and determinants. Economic and Political Weekly, 39 (7), pp 671-676.

Ray, R. (2007). Changes in Food Consumption and the Implications for Food Security and Undernourishment: India in the 1990s. Development and Change 38(2), 321 - 343.

Reynolds, AJ, Temple, JA, Robertson DL \& Mann EA (2001). Long-Term Effects of an Early Childhood Intervention on Educational Achievement and Juvenile Arrest: A 15Year Follow-Up of Low-Income Children in Public Schools. Journal of the American Medical Association, 285 (18), pp. 2330-2346.

Right to Food Campaign (2007). Anganwadis for all: a primer. New Delhi (restricted circulation. URL: http://www.righttofoodindia.org/data/icds06primer.pdf Accessed 29 January 2011), Delhi.

Samvad V. Moribund ICDS: a study on the ICDS and Child Survival issues in Madhya Pradesh. Right to Food Campaign Madhya Pradesh Support Group, Vikas Samvad and Sanket-Centre for Budget Studies, Bhopal. URL:

http:// southasia.oneworld.net/Files/ICDS.pdf Accessed 29 January 2011.

Subramanyam, MA, Kawachi, I, Berkman, LF \& Subramanian SV (2010). Socioeconomic inequalities in childhood undernutrition in India: analyzing trends between 1992 and 2005. PLoS One. 5(6): e11392.

Tarozzi, A (2002). The Indian Public Distribution System as provider of food security: evidence from child anthropometry in Andhra Pradesh. Princeton University, Economics Paper 185, 208 Fisher Hall, Princeton, NJ 08544.

Tarozzi, A. and A. Mahajan (2007). Child Nutrition in India in the Nineties. Economic Development and Cultural Change, 55(3), 441 - 486.

Times of India. Anganwadi workers' agitation on Thursday. January 31, 2011. URL: http:/ / timesofindia.indiatimes.com/city/guwahati/Anganwadi-workersagitation-on-Thursday/articleshow/7393484.cms Accessed 31 January 2011.

Udani RH, Chothani S, Arora S, Kulkarni CS. (1990). Evaluation of knowledge and efficiency of Anganwadi workers. Indian Journal of Paediatrics, 47 (4), pp 289-292.

UNESCO (2010). Global Education Digest 2010. UNESCO Institute of Statistics, ISBN: 978-929189-088-0, Quebec.

United Nations (2010). Millennium Development Goals 2010. New York: United Nations, ISBN 978-92-1-101218-7, New York.

Vijayaraghavan, KN, Rao, NP, Sarma R, Reddy V. (1984) impact of massive doses of Vitamin A on incidence of nutritional blindness. The Lancet 324, Issue 8395, pp 149-151.

World Health Organisation South East Asia Regional Office (2009). Report of the regional consultation on measles. WHO, SEA-Immun-57, New Delhi.

World Health Organization (2009). Global Health Risks: mortality and burden of disease attributable to selected major risks. WHO, ISBN 978924156387 1, Geneva.

World Health Organization (2009b). Global prevalence of vitamin A deficiency in populations at risk 1995-2005. WHO, ISBN 978924159801 9, Geneva.

World Health Organization (2008). The World Health Report 2008: primary health care now more than ever. Geneva: World Health Organization, 2008.

World Health Organisation (2008). Worldwide prevalence of anaemia 1993-2005. WHO, ISBN 978924159665 7, Geneva.

Young, M. (1996). Early Child Development: Investing in the Future. The World Bank, ISBN 08213-3547-2, Washington, DC. 


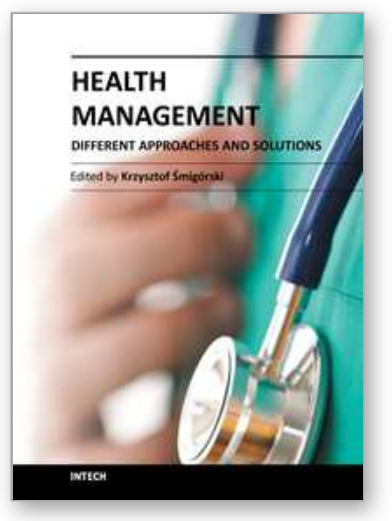

\author{
Health Management - Different Approaches and Solutions \\ Edited by Dr. Krzysztof Smigorski
}

ISBN 978-953-307-296-8

Hard cover, 498 pages

Publisher InTech

Published online 14, December, 2011

Published in print edition December, 2011

The development in our understanding of health management ensures unprecedented possibilities in terms of explaining the causes of diseases and effective treatment. However, increased capabilities create new issues. Both, researchers and clinicians, as well as managers of healthcare units face new challenges: increasing validity and reliability of clinical trials, effectively distributing medical products, managing hospitals and clinics flexibly, and managing treatment processes efficiently. The aim of this book is to present issues relating to health management in a way that would be satisfying for academicians and practitioners. It is designed to be a forum for the experts in the thematic area to exchange viewpoints, and to present health management's stateof-art as a scientific and professional domain.

\title{
How to reference
}

In order to correctly reference this scholarly work, feel free to copy and paste the following:

Niyi Awofeso and Anu Rammohan (2011). Three Decades of the Integrated Child Development Services Program in India: Progress and Problems, Health Management - Different Approaches and Solutions, Dr. Krzysztof Smigorski (Ed.), ISBN: 978-953-307-296-8, InTech, Available from:

http://www.intechopen.com/books/health-management-different-approaches-and-solutions/three-decades-ofthe-integrated-child-development-services-program-in-india-progress-and-problems

\section{INTECH}

open science | open minds

\author{
InTech Europe \\ University Campus STeP Ri \\ Slavka Krautzeka 83/A \\ 51000 Rijeka, Croatia \\ Phone: +385 (51) 770447 \\ Fax: +385 (51) 686166 \\ www.intechopen.com
}

\author{
InTech China \\ Unit 405, Office Block, Hotel Equatorial Shanghai \\ No.65, Yan An Road (West), Shanghai, 200040, China \\ 中国上海市延安西路65号上海国际贵都大饭店办公楼 405 单元 \\ Phone: +86-21-62489820 \\ Fax: +86-21-62489821
}


(C) 2011 The Author(s). Licensee IntechOpen. This is an open access article distributed under the terms of the Creative Commons Attribution 3.0 License, which permits unrestricted use, distribution, and reproduction in any medium, provided the original work is properly cited. 